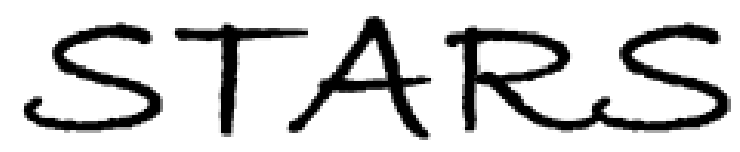

University of Central Florida

STARS

$1-1-2008$

\title{
Effect of carbon addition on the glass-forming ability of mechanically alloyed Fe-based alloys
}

Satyajeet Sharma

University of Central Florida

C. Suryanarayana

University of Central Florida

Find similar works at: https://stars.library.ucf.edu/facultybib2000

University of Central Florida Libraries http://library.ucf.edu

This Article is brought to you for free and open access by the Faculty Bibliography at STARS. It has been accepted for inclusion in Faculty Bibliography 2000 s by an authorized administrator of STARS. For more information, please contact STARS@ucf.edu.

\section{Recommended Citation}

Sharma, Satyajeet and Suryanarayana, C., "Effect of carbon addition on the glass-forming ability of mechanically alloyed Fe-based alloys" (2008). Faculty Bibliography 2000s. 973.

https://stars.library.ucf.edu/facultybib2000/973

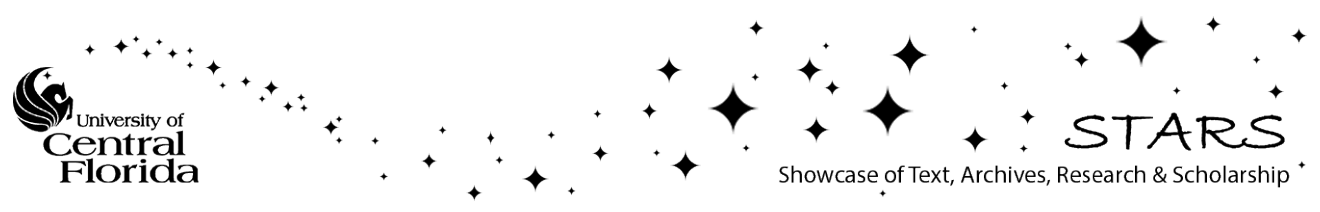




\section{Effect of carbon addition on the glass- forming ability of mechanically alloyed Fe- based alloys}

Cite as: J. Appl. Phys. 103, 013504 (2008); https://doi.org/10.1063/1.2828152

Submitted: 06 September 2007 . Accepted: 01 November 2007. Published Online: 03 January 2008

Satyajeet Sharma, and C. Suryanarayana

\section{ARTICLES YOU MAY BE INTERESTED IN}

New Fe-based soft magnetic alloys composed of ultrafine grain structure Journal of Applied Physics 64, 6044 (1988); https://doi.org/10.1063/1.342149

Exceptionally high glass-forming ability of an FeCoCrMoCBY alloy

Applied Physics Letters 86, 151907 (2005); https://doi.org/10.1063/1.1897426

Bulk amorphous alloys with high mechanical strength and good soft magnetic properties in Fe-TM-B (TM=IV-VIII group transition metal) system

Applied Physics Letters 71, 464 (1997); https://doi.org/10.1063/1.119580

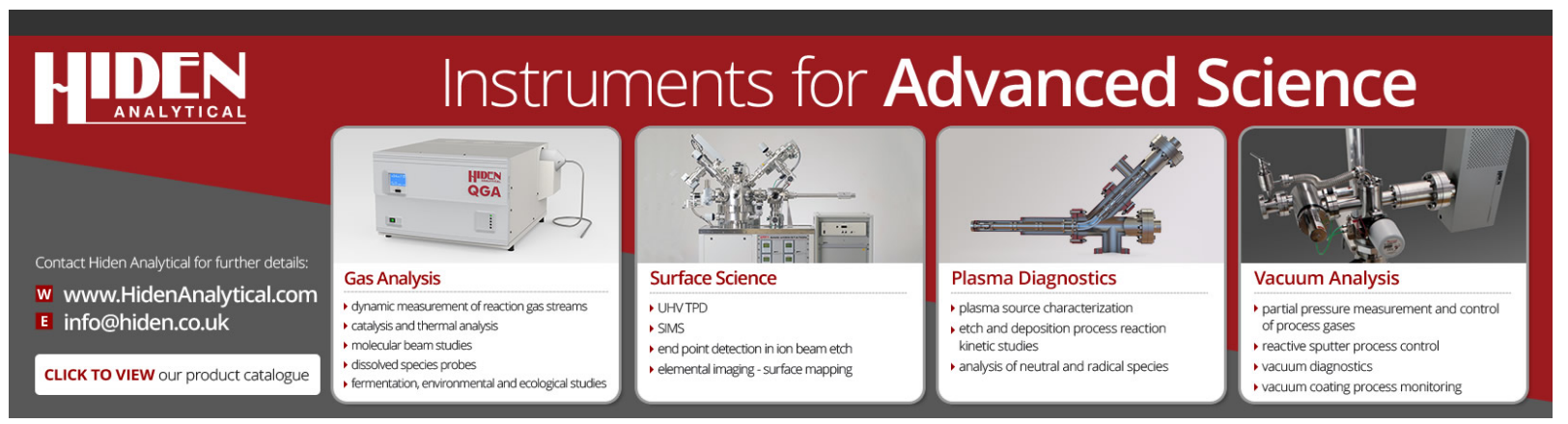




\title{
Effect of carbon addition on the glass-forming ability of mechanically alloyed Fe-based alloys
}

\author{
Satyajeet Sharma and C. Suryanarayana ${ }^{a)}$ \\ Department of Mechanical, Materials and Aerospace Engineering, University of Central Florida, Orlando, \\ Florida 32816-2450, USA
}

(Received 6 September 2007; accepted 1 November 2007; published online 3 January 2008)

The effect of carbon addition on the glass-forming ability (GFA) of mechanically alloyed Fe-based $\mathrm{Fe}_{42} \mathrm{M}_{28} \mathrm{Zr}_{10} \mathrm{~B}_{20}(\mathrm{M}=\mathrm{Ni}, \mathrm{Al}$, or $\mathrm{Ge})$ amorphous alloy systems was investigated. It was shown that when $\mathrm{B}$ was partially replaced by 10 at. $\% \mathrm{C}$ in the $\mathrm{Fe}-\mathrm{Ni}-\mathrm{Zr}-\mathrm{B}$ and $\mathrm{Fe}-\mathrm{Al}-\mathrm{Zr}-\mathrm{B}$ alloy systems, the GFA of the systems had increased significantly, as determined by the reduced milling time required for amorphization. However, when carbon was added to the Fe-Ge-Zr-B alloy system, the GFA was decreased drastically and no amorphization was observed. The role of carbon on the GFA of alloy systems has been discussed from the thermodynamic and kinetic points of view.

(C) 2008 American Institute of Physics. [DOI: 10.1063/1.2828152]

\section{INTRODUCTION}

Metallic glasses or amorphous alloys have an attractive combination of physical, chemical, mechanical, and magnetic properties. Consequently, they have already found commercial applications and other applications are being explored. ${ }^{1-5}$ However, during the last several years, more attention has been paid to the structure and properties of bulk metallic glasses (BMG's), glassy alloys that could be produced in large section thicknesses or diameters reaching several tens of millimeters. ${ }^{6-10}$ The largest section thickness (or diameter) that could be achieved is a function of the base metal and alloy composition, amongst other parameters. The largest rod diameter obtained in Fe-based BMG's is only about $16 \mathrm{~mm},{ }^{11}$ while the largest diameter of $72 \mathrm{~mm}$ that has been achieved in any of the BMG's is in a $\mathrm{Pd}-(10$ at. \% $)$ $\mathrm{Ni}-(30$ at. $\%) \mathrm{Cu}-\left(20\right.$ at. \%) $\mathrm{P}$ alloy. ${ }^{12}$ The ability to produce glassy alloys in larger section thicknesses enables exploitation of these advanced materials for a variety of different applications.

The production of BMG's by consolidation of amorphous powders is another promising method in the near-netshape fabrication of amorphous materials. Such a situation is possible by producing the amorphous alloy powders via methods such as mechanical alloying (MA) and subsequently consolidating them to bulk specimens using conventional hot isostatic pressing, hot extrusion, or other methods. ${ }^{13}$ In comparison to the solidification route, MA is an inexpensive and simpler technique to process the material into an amorphous state. Further, it is easier to produce the amorphous phase in a much wider composition range by MA than by solidification methods. Additionally, since MA processing is carried out in the solid state, phase diagram restrictions do not seem to apply to the phases produced by the technique. However, due to the large number of variables in the MA process, optimization of parameters becomes essential for obtaining consistent results. ${ }^{14,15}$

\footnotetext{
${ }^{a)}$ Author to whom correspondence should be addressed. Electronic mail: csuryana@mail.ucf.edu.
}

Amorphous alloy powders come into close contact with carbon dies and punches during hot pressing or other consolidation methods and therefore carbon contamination is likely an important concern. Thus, it is useful to evaluate the stability of amorphous alloys in presence of carbon by possibly designing alloy compositions which contain carbon as an additional alloying element. Thus, we report in this paper, the effect of carbon addition on the glass-forming ability (GFA) of Fe-based quaternary alloy systems with a base composition of $\mathrm{Fe}_{42} \mathrm{M}_{28} \mathrm{Zr}_{10} \mathrm{~B}_{20}$ (where $\mathrm{M}=\mathrm{Ni}$, $\mathrm{Al}$, or $\mathrm{Ge}$ ). We had earlier reported that all these three systems could be easily amorphized by milling the blended elemental powders for 20,10 , and $10 \mathrm{~h}$, respectively. ${ }^{16}$ Since the metalloid content in amorphous alloys is generally around 20 at. \%, the compositions of alloys studied in this investigation were chosen to satisfy this requirement. Accordingly, part of boron was replaced by carbon (at 10 at. \% level). This carbon content is at a much higher level in comparison to the 3,4 , and 5 at. $\%$ as studied earlier by Wang and co-workers, ${ }^{17,18}$ Kim et al. ${ }^{19}$ and Inoue et al.,${ }^{20}$ respectively.

\section{EXPERIMENTAL PROCEDURE}

Alloy compositions of $\mathrm{Fe}-\mathrm{M}-\mathrm{Zr}-\mathrm{B}(\mathrm{M}=\mathrm{Ni}, \mathrm{Al}$, or $\mathrm{Ge})$ that were shown to amorphize by MA earlier were selected to study the effect of carbon addition. Elemental powders of 99.9\% purity were blended to a composition of $\mathrm{Fe}_{42} \mathrm{M}_{28} \mathrm{Zr}_{10} \mathrm{C}_{10} \mathrm{~B}_{10}$. The subscripts represent the atomic percentage of elements in the powder mix. MA was carried out in a SPEX $8000 \mathrm{D}$ shaker mill with a ball-to-powder weight ratio maintained at 10:1. The weighing, blending, and loading of the powders was carried out inside an argon-filled glove box so as to minimize powder contamination. For every composition, $5 \mathrm{~g}$ of blended elemental powder was loaded inside a stainless steel vial with $50 \mathrm{~g}$ of hardened steel balls. The ball diameters used were of 5 and $8 \mathrm{~mm}$, so as to attain a better milling behavior. The evolution of structure during milling was monitored by collecting the milled powder samples at regular intervals of milling, and analyzed by the $\mathrm{x}$-ray diffraction (XRD) and transmission electron mi- 


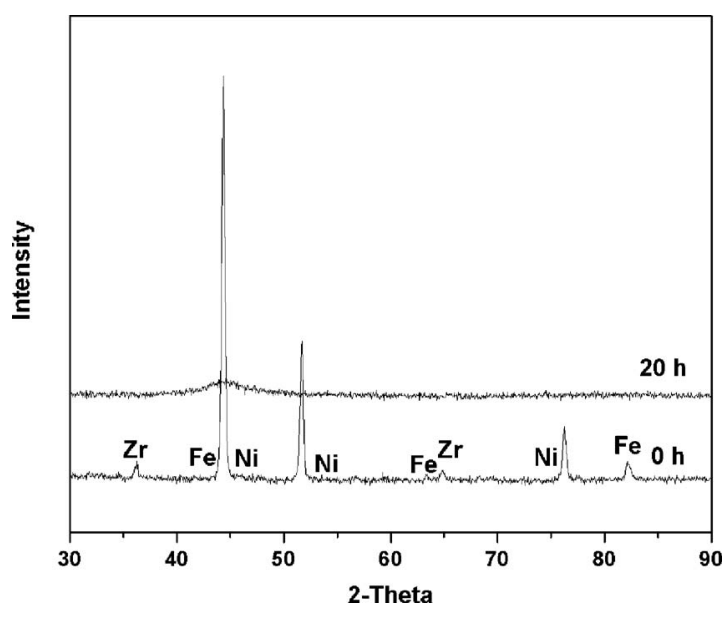

FIG. 1. XRD patterns of the $\mathrm{Fe}_{42} \mathrm{Ni}_{28} \mathrm{Zr}_{10} \mathrm{~B}_{20}$ powder (without carbon addition) in the as-blended condition and after milling for $20 \mathrm{~h}$. The as-blended powder shows the presence of all the expected diffraction peaks. The powder milled for $20 \mathrm{~h}$ shows the presence of a broad diffuse halo indicating the presence of a fully amorphous phase.

croscoopy (TEM) techniques. XRD patterns were recorded using a Rigaku x-ray diffractometer with $\mathrm{Cu} K \alpha$ radiation $(\lambda=0.15406 \mathrm{~nm})$ in the $2 \theta$ range from $30^{\circ}$ to $90^{\circ}$, and TEM studies were conducted using a Tecnai F30 transmission electron microscope operating at $300 \mathrm{kV}$ and equipped with an energy dispersive analyzer.

\section{RESULTS}

Figure 1 shows the XRD patterns of the $\mathrm{Fe}_{42} \mathrm{Ni}_{28} \mathrm{Zr}_{10} \mathrm{~B}_{20}$ powder (without carbon addition) in the as-blended condition $(0 \mathrm{~h}$ of milling) and also after milling the powder for $20 \mathrm{~h}$. While all the expected diffraction peaks of $\mathrm{Fe}, \mathrm{Ni}$, and $\mathrm{Zr}$ are seen in the as-blended powder, boron peaks are not seen because of its low atomic scattering factor and also because it is amorphous. On the other hand, the XRD pattern of the powder milled for $20 \mathrm{~h}$ clearly shows the presence of a broad diffuse halo indicating the presence of an amorphous phase.

To confirm the nature of the phase(s) in the powder milled for $20 \mathrm{~h}$, TEM investigations were conducted. Figure 2 shows the TEM micrographs and diffraction patterns of the powder milled for $20 \mathrm{~h}$. Figure 2(a) shows a diffraction pattern from the sample, which shows that the milled powder is fully amorphous in nature. However, on observation of the sample in the TEM, the intense electron beam appears to promote (at least partial) crystallization of the amorphous phase. Consequently, a few very tiny crystals of about $10-15 \mathrm{~nm}$ size (indicated by arrows) are also occasionally seen inside an amorphous matrix [Fig. 2(b)]. Figure 2(c) shows the corresponding diffraction pattern from this structure. It consists of mostly a diffuse ring indicating that the major phase is an amorphous phase, onto which some sharp diffraction spots are superimposed. These diffraction spots could be indexed to an Fe phase with a bec structure and with the expected lattice parameter.

Figure 3 shows the structural evolution in the blended elemental powder mixture of $\mathrm{Fe}_{42} \mathrm{Ni}_{28} \mathrm{Zr}_{10} \mathrm{C}_{10} \mathrm{~B}_{10}$ as a function of milling time. The as-blended powder mix showed the presence of all the diffraction peaks expected from the me-

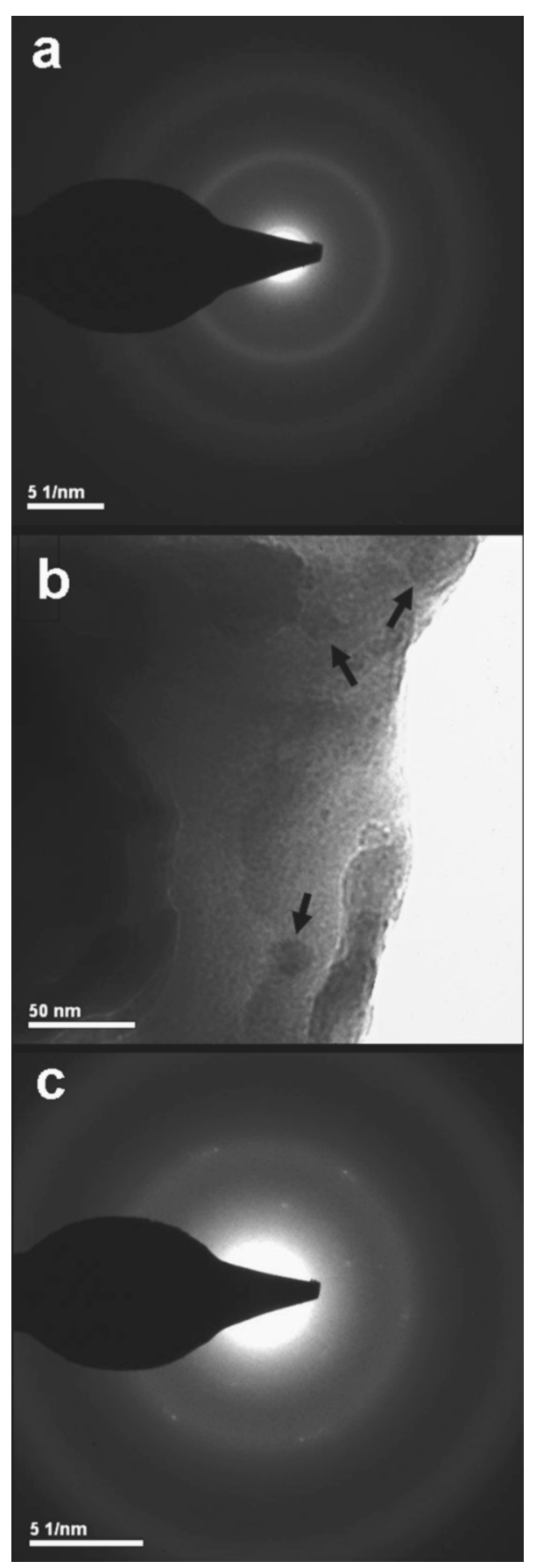

FIG. 2. Transmission electron micrographs of $\mathrm{Fe}_{42} \mathrm{Ni}_{28} \mathrm{Zr}_{10} \mathrm{~B}_{20}$ (without carbon addition) powder milled for $20 \mathrm{~h}$ to confirm the presence of different phases. (a) Diffraction pattern from the fully amorphous phase. The diffuse ring confirms the presence of an amorphous phase. (b) Bright-field electron micrograph showing the presence of mostly an amorphous phase and a few tiny crystals about $10-15 \mathrm{~nm}$ in size. (c) Diffraction pattern from (b) showing the diffuse halo on which a few sharp diffraction spots are superimposed. These diffraction spots are indexed to the bcc iron phase.

tallic elements. Diffraction peaks of B and C were not seen due to their low scattering factor, and probably due to the amorphous nature of boron (and carbon). Formation of the amorphous phase is noted on milling the powder blend for $8 \mathrm{~h}$ which is evidenced by the appearance of a broad diffuse peak with a maximum corresponding to where the crystalline $(110)_{\mathrm{Fe}}$ peak was expected to be present. The homogeneous amorphous phase in this powder blend is stable until about 


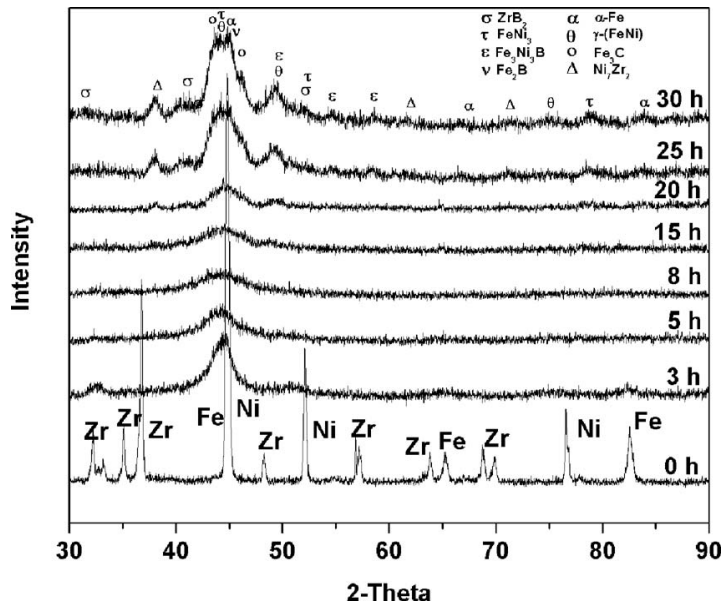

FIG. 3. XRD patterns of blended elemental powder mix of $\mathrm{Fe}_{42} \mathrm{Ni}_{28} \mathrm{Zr}_{10} \mathrm{C}_{10} \mathrm{~B}_{10}$ as a function of milling time. Note that the glassy phase is formed on milling the powder for $8 \mathrm{~h}$ and is found to be stable till $15 \mathrm{~h}$. Mechanical crystallization is noted to occur from around $20 \mathrm{~h}$. The intensities of the crystalline peaks of the different phases increased beyond this milling time, and some of these intermetallics are identified in the pattern recorded from the powder milled for $30 \mathrm{~h}$.

$15 \mathrm{~h}$ of milling time. At a later stage, from about $20 \mathrm{~h}$, formation of some crystalline phases is noted as a result of mechanical crystallization of the amorphous phase. The mechanical crystallization is clearly evident on milling the powder blend for about $30 \mathrm{~h}$, as indicated by the relatively intense diffraction peaks of the different phases. Formation of several phases along with the $\alpha$-Fe solid solution is noted in the powder blend at $30 \mathrm{~h}$ of milling time.

Figure 4 shows the XRD patterns of the $\mathrm{Fe}_{42} \mathrm{Al}_{28} \mathrm{Zr}_{10} \mathrm{C}_{10} \mathrm{~B}_{10}$ powder mix as a function of milling time. Formation of $\alpha$-Fe solid solution was clearly noted at short milling times, indicated by the presence of low intensity crystalline peaks at $5 \mathrm{~h}$ of milling time. Subsequent mill-

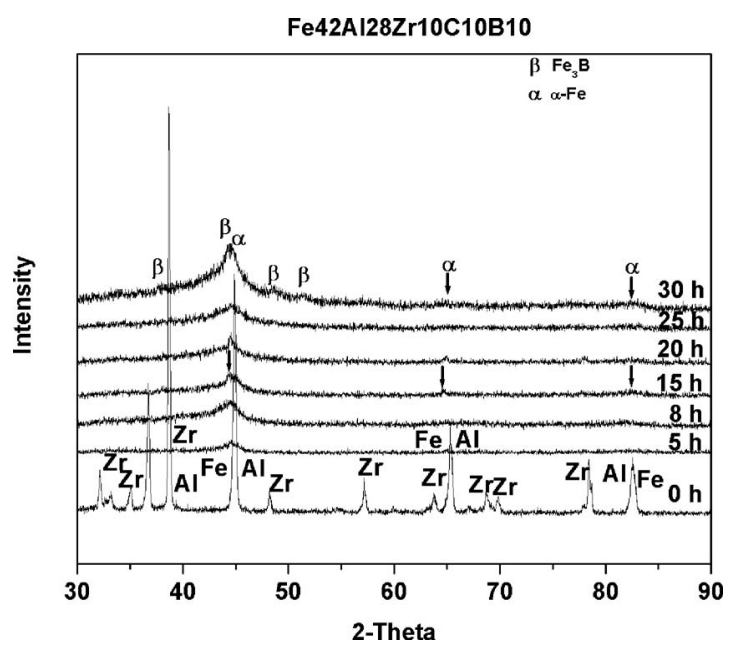

FIG. 4. XRD patterns of the blended elemental powder mix of $\mathrm{Fe}_{42} \mathrm{Al}_{28} \mathrm{Zr}_{10} \mathrm{C}_{10} \mathrm{~B}_{10}$ as a function of milling time. Note that the glassy phase formed on milling the powder for 5-8 h. Mechanical crystallization is observed to take place from about $15 \mathrm{~h}$, evidenced by the formation of low intensity crystalline peaks, marked by arrows. It is noted that after crystallization, there is a tendency for reamorphization at $25 \mathrm{~h}$ (but a very small amount of crystalline phase may be present). Reasonably intense peaks of some crystalline phases are observed beyond this milling time, say, at $30 \mathrm{~h}$.

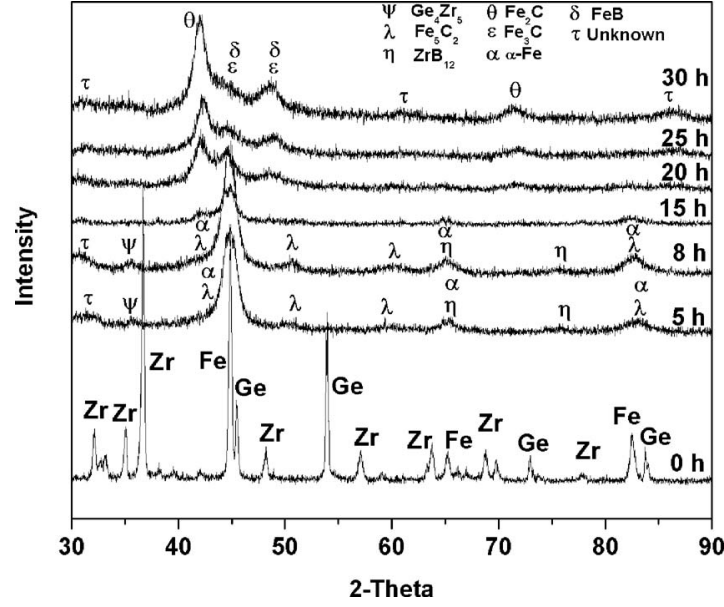

FIG. 5. XRD patterns of the blended elemental powder mix of $\mathrm{Fe}_{42} \mathrm{Ge}_{28} \mathrm{Zr}_{10} \mathrm{C}_{10} \mathrm{~B}_{10}$ as a function of milling time. Formation of $\alpha$-Fe-solid solution is observed at $5 \mathrm{~h}$ of milling time along with some compounds based on the other elements in the blend. Milling for long times (say, $30 \mathrm{~h}$ ) transforms the alloy system into a combination of several interstitial compounds.

ing led to the formation of an amorphous phase. From the diffraction patterns, it appears that amorphization is occurring on milling the powder for a time between 5 and $8 \mathrm{~h}$. On further milling, mechanical crystallization of the glassy phase commences at around $15 \mathrm{~h}$, which is evidenced by the formation of low intensity crystalline peaks, marked by arrows. The stability of the amorphous phase does not appear to be significantly different between the Ni-containing and Al-containing compositions. For example, low intensity crystalline peaks of $\alpha$-Fe start appearing in the Al-containing alloy after milling the powder for $15 \mathrm{~h}$. A set of low intensity crystalline peaks start appearing around this time of milling in the Ni-containing alloy also. But, the nature of the crystalline phase(s) forming in this alloy composition appears to be different. This becomes more prominent at longer milling times. At the longest milling time recorded, the number and amount of crystalline phases seems to be more in the Nicontaining alloy than in the Al-containing alloy. The diffraction pattern for the Ni-containing alloy at $30 \mathrm{~h}$ of milling time shows more and also relatively high intensity peaks (compare Figs. 3 and 4). But, an important difference between these two alloy compositions is that the $\mathrm{Fe}_{42} \mathrm{Al}_{28} \mathrm{Zr}_{10} \mathrm{C}_{10} \mathrm{~B}_{10}$ alloy system shows a tendency for reamorphization on milling the powder for about $25 \mathrm{~h}$. This is somewhat similar to the cyclic crystalline $\rightarrow$ amorphous $\rightarrow$ crystalline transformations observed in some alloy systems. ${ }^{21-25}$

Figure 5 shows the XRD patterns for the $\mathrm{Fe}_{42} \mathrm{Ge}_{28} \mathrm{Zr}_{10} \mathrm{C}_{10} \mathrm{~B}_{10}$ blended elemental powder mixture as a function of milling time. Interestingly, the quinary system with carbon addition did not show any signs of amorphization. This should be contrasted with the $\mathrm{Fe}_{42} \mathrm{Ge}_{28} \mathrm{Zr}_{10} \mathrm{~B}_{20}$ quaternary system (i.e., without carbon) in which the amorphous phase had formed in $10 \mathrm{~h}$ during MA. ${ }^{16}$ As evident from Fig. 5, at the initial stages of milling, the $\alpha$-Fe solid solution is present along with some other phases. With continued milling, interstitial compounds based on $\mathrm{Zr}$ and $\mathrm{Fe}$ and some intermetallics seem to have formed. It is also ob- 
TABLE I. Comparison of milling times required for amorphization with and without addition of $\mathrm{C}$ to $\mathrm{Fe}_{42} \mathrm{M}_{28} \mathrm{Zr}_{10} \mathrm{~B}_{20}$ alloy system ( $\mathrm{M}=\mathrm{Al}, \mathrm{Ni}$, or $\left.\mathrm{Ge}\right)$.

\begin{tabular}{cccc}
\hline \hline $\begin{array}{c}\text { Quaternary system } \\
\text { without carbon }\end{array}$ & $\begin{array}{c}\text { Milling time for } \\
\text { amorphization }(h)\end{array}$ & $\begin{array}{c}\text { Quinary system } \\
\text { with carbon }\end{array}$ & $\begin{array}{c}\text { Milling time for } \\
\text { amorphization }(h)\end{array}$ \\
\hline $\mathrm{Fe}_{42} \mathrm{Ni}_{28} \mathrm{Zr}_{10} \mathrm{~B}_{20}$ & 20 & $\mathrm{Fe}_{42} \mathrm{Ni}_{28} \mathrm{Zr}_{10} \mathrm{C}_{10} \mathrm{~B}_{10}$ & 8 \\
$\mathrm{Fe}_{42} \mathrm{Al}_{28} \mathrm{Zr}_{10} \mathrm{~B}_{20}$ & 10 & $\mathrm{Fe}_{42} \mathrm{Al}_{28} \mathrm{Zr}_{10} \mathrm{C}_{10} \mathrm{~B}_{10}$ & $5-8$ \\
$\mathrm{Fe}_{42} \mathrm{Ge}_{28} \mathrm{Zr}_{10} \mathrm{~B}_{20}$ & 10 & $\mathrm{Fe}_{42} \mathrm{Ge}_{28} \mathrm{Zr}_{10} \mathrm{C}_{10} \mathrm{~B}_{10}$ & No amorphization \\
\hline \hline
\end{tabular}

served from this figure that on milling for a long time, the solid solution formed at the early stages of milling, has transformed into carbides and borides. An unidentified phase (along with other phases) is observed at $30 \mathrm{~h}$ of milling time.

Results of the effect of $\mathrm{C}$ addition with respect to the three quaternary systems studied in this investigation are summarized in Table I. The results clearly show the improvement of GFA in alloy systems containing $\mathrm{Ni}$ and $\mathrm{Al}$, where the milling time for amorphization has decreased from 20 to $8 \mathrm{~h}$ in the case of $\mathrm{Fe}-\mathrm{Ni}-\mathrm{Zr}-\mathrm{C}-\mathrm{B}$ and from 10 to $5-8 \mathrm{~h}$ in the case of $\mathrm{Fe}-\mathrm{Al}-\mathrm{Zr}-\mathrm{C}-\mathrm{B}$. In contrast, the $\mathrm{Fe}-\mathrm{Ge}-\mathrm{Zr}-\mathrm{C}-\mathrm{B}$ alloy system showed a reduced GFA, and amorphization was not very clearly observed.

\section{DISCUSSION}

The XRD patterns presented in Figs. 3-5 and the results summarized in Table I show that addition of 10 at. \% $\mathrm{C}$ has a significant effect on the GFA of the Fe-based alloy systems investigated here. While the $\mathrm{Ni}$ - and Al-containing alloys have shown improved GFA, the one with Ge showed a decreased GFA and did not show amorphization on addition of carbon.

Wang and co-workers ${ }^{17,18}$ showed that while a small amount of carbon addition (up to about 1 at. \%) increased the GFA of Zr-based glassy alloy systems, devitrification (crystallization) was noted on increasing the $\mathrm{C}$ content to about 3 at. \% or higher. That is, higher carbon concentrations in the alloy led to crystallization of the amorphous phase formed. In another study, Kim et al. ${ }^{19}$ fabricated Misch metal-based BMG's and noted that the GFA of these alloys was enhanced with the addition of 4 at. \% carbon. In comparison to the above studies, we find our results quite novel and important for processing of Fe-based amorphous alloys. In our study, the effect of carbon addition is seen to be varying depending on the constituent elements in the alloy. From Table I it is noted that the carbon addition enhances the GFA of Ni- and Al-containing Fe-based alloys and that it has a much more significant effect on the GFA of the Nicontaining system than on the Al-containing system. This is because the time required for the formation of the amorphous phase was brought down from 20 to $8 \mathrm{~h}$ in the $\mathrm{Ni}$-containing system, whereas it was brought down to $5-8 \mathrm{~h}$ from $10 \mathrm{~h}$ in the Al-containing system.

Even though the effect of carbon addition is seen to increase the GFA of the two alloy systems containing $\mathrm{Al}$ and $\mathrm{Ni}$, an important difference noted is that reamorphization seems to take place in the Al-containing alloy system. In other words, the Al-containing system possesses a tendency to resist crystallization. Further, it is also noted that the num- ber of phases is much less and with relatively low intensity peaks at the end of milling for $30 \mathrm{~h}$, as seen in Fig. 4. Since crystallization is a kinetic process and it requires time for the crystalline phases to form, this reamorphized phase would require a much longer time for sufficient amount of the crystalline phases to form. Milling for a longer time, say, for $50 \mathrm{~h}$, would perhaps produce a much larger amount of the crystalline phases in the Al-containing alloy. This could explain why the number and intensity of the crystalline peaks is higher in the Ni-containing alloy and less in the Alcontaining alloy.

In the system containing $\mathrm{Ge}$, however, the results were unexpected since, in our earlier study, the quaternary $\mathrm{Fe}-\mathrm{Ge}-$ $\mathrm{Zr}-\mathrm{B}$ showed good GFA, ${ }^{16}$ whereas a detrimental effect on glass formation was observed when $\mathrm{C}$ was added.

The role of carbon on the GFA of alloys can be discussed on the basis of its kinetic and thermodynamic aspects. It is known that the presence of metalloid atoms disrupts the short-range order of the type necessary for the formation of crystal nuclei and thus can lead to formation of an amorphous phase. ${ }^{26}$ This seems to be due to the small size of metalloid atoms as compared with the metal atoms among which they are mixed. Also, due to the strong attractive bonds present between neighboring metal-metalloid pairs, ${ }^{27,28}$ the metalloid atoms tend to avoid each other as neighbors. That is why the metalloid atoms are surrounded by metal atoms forming clusters. Furthermore, the addition of carbon atoms increases the degree of dense random packing of the alloy system. Additionally, since the diameter of the carbon atom $(0.142 \mathrm{~nm})$ is much smaller than that of Fe $(0.248 \mathrm{~nm}), \quad \mathrm{Zr} \quad(0.318 \mathrm{~nm}), \quad \mathrm{Ni} \quad(0.250 \mathrm{~nm}), \quad$ or $\mathrm{Al}$ $(0.286 \mathrm{~nm})$, this large difference in atomic size suppresses the long-range interdiffusion required for crystallization. All these factors enhance the GFA, as indicated by the reduced milling time required for amorphization.

Looking at the thermodynamic aspects, carbon has positive heat of mixing with $\mathrm{Fe}\left(+40 \mathrm{~kJ} \mathrm{~mole}^{-1}\right), \mathrm{Ni} \quad(+51$ $\left.\mathrm{kJ} \mathrm{mole}^{-1}\right)$, and $\mathrm{Al}\left(+54 \mathrm{~kJ} \mathrm{~mole}^{-1}\right)$, and a large negative heat of mixing with $\mathrm{Zr}\left(-98 \mathrm{~kJ}\right.$ mole $\left.{ }^{-1}\right){ }^{29}$ Also, other constituent elements (e.g., $\mathrm{Zr}$ and $\mathrm{B}$ ) have a negative heat of mixing, thus satisfying Inoue's empirical criteria for glass formation. ${ }^{6,9}$ Consequently, the presence of elements with a combination of positive and negative enthalpies of mixing frustrates the formation of competing crystalline phases, as seen in the studies by Park et al. ${ }^{30,31}$ Therefore, we observe an increase in the GFA for the $\mathrm{Fe}-\mathrm{Ni}-\mathrm{Zr}-\mathrm{C}-\mathrm{B}$ and $\mathrm{Fe}-\mathrm{Al}-$ $\mathrm{Zr}-\mathrm{C}-\mathrm{B}$ alloy systems.

It has been observed that in Fe-based alloys containing metalloids, the major crystalline phases coexisting with the 
glassy matrix are always the Fe-metalloid-type compounds. ${ }^{32}$ In our study, the atomic size differences among the constituent elements are much more in the Al-containing system than in the Ni-containing system. Accordingly, the dense random packing of atoms is higher in the Al-containing system, which is appropriate for amorphization. Further, the strong bonding between $\mathrm{Al}$ and $\mathrm{B} / \mathrm{C}$ atoms causes formation of $\mathrm{Al}-\mathrm{C}$ and $\mathrm{Al}-\mathrm{B}$ atomic pairs in the glassy phase. The presence of these Al-metalloid pairs prevents the atomic rearrangement required for the precipitation of the major crystalline phases of the Fe-metalloid compounds in the $\mathrm{Fe}-\mathrm{Al}-\mathrm{Zr}$ C-B system. Thus, the tendency to resist crystallization, or increased tendency for amorphization, can be rationalized in the $\mathrm{Fe}-\mathrm{Al}-\mathrm{Zr}-\mathrm{C}-\mathrm{B}$ alloy system.

Sinclair et al. ${ }^{33}$ have proposed a mechanism, wherein the crystallization temperature of an amorphous phase could be significantly reduced in the presence of some metals, particularly those that form a eutectic phase diagram with $\mathrm{Si}$ and Ge. This is known as metal-mediated crystallization. It was shown ${ }^{34}$ by high-resolution transmission electron microscopy methods that the mechanism involves dissolution of the amorphous element (e.g., carbon) in the matrix thereby supersaturating it. Subsequently, precipitation of the solute atoms in the metal matrix, followed by the diffusion of atoms from the amorphous to crystalline nuclei, initiates the reaction at much lower temperature than can occur in the elemental matrix. In our case, $\mathrm{Fe}-\mathrm{Ge}$ alloy system features a eutectic reaction as seen from the binary phase diagram ${ }^{35}$ and thus, addition of carbon which is amorphous in nature, induces crystallization, thus explaining the nonamorphization behavior of the $\mathrm{Fe}-\mathrm{Ge}-\mathrm{Zr}-\mathrm{C}-\mathrm{B}$ alloy system.

\section{CONCLUSIONS}

The glass-forming ability (GFA) of some mechanically alloyed Fe-based alloy systems was improved by the addition of carbon. It was also seen that the amount of carbon can be increased to as high as 10 at. \% without any negative effect on glass formation in some of the systems. This aspect becomes important in consolidation of amorphous alloy powders where carbon dies are commonly used and carbon pickup by the powder compact is inevitable. Alloy systems with the composition $\mathrm{Fe}_{42} \mathrm{Ni}_{28} \mathrm{Zr}_{10} \mathrm{C}_{10} \mathrm{~B}_{10}$ and $\mathrm{Fe}_{42} \mathrm{Al}_{28} \mathrm{Zr}_{10} \mathrm{C}_{10} \mathrm{~B}_{10}$ show an improvement in GFA which is indicated by the shorter milling times (in contrast to the quaternary systems without carbon) required for amorphization. On the other hand, the alloy composition containing $\mathrm{Ge}$ $\left(\mathrm{Fe}_{42} \mathrm{Ge}_{28} \mathrm{Zr}_{10} \mathrm{C}_{10} \mathrm{~B}_{10}\right)$ showed a drastic decrease in GFA with the carbon addition, and no amorphous phase formation was noted. The role of carbon addition has been attributed to the atomic size effects, its positive heat of mixing with some constituent elements, and metal-mediated crystallization which occurs in the Ge-containing system.

\section{ACKNOWLEDGMENTS}

This research work was supported in part by National Science Foundation under Grant No. DMR-0314212. The authors are grateful to Mr. Uma M.R. Seelam for help in the transmission electron microscopy work.

${ }^{1}$ F. E. Luborsky, Amorphous Metallic Alloys (Butterworths, London, 1983). ${ }^{2}$ C. Suryanarayana, Bull. Mater. Sci. 6, 579 (1984).

${ }^{3}$ Metallic Glasses: Production, Properties and Applications, edited by T. R. Anantharaman (Trans Tech, Aedermannsdorf, Switzerland, 1984).

${ }^{4} \mathrm{R}$. W. Cahn, in Materials Science and Technology: A Comprehensive Treatment, edited by J. Zarzycki (Wiley VCH, Weinheim, 1991), Vol. 9, pp. 493-548.

${ }^{5}$ Rapidly Solidified Alloys: Processes, Structures, Properties, and Applications, edited by H. H. Liebermann (Marcel Dekker, New York, 1993).

${ }^{6}$ A. Inoue, Acta Mater. 48, 279 (2000).

${ }^{7}$ W. L. Johnson, MRS Bull. 24(10), 42 (1999).

${ }^{8}$ J. F. Löffler, Intermetallics 11, 529 (2003).

${ }^{9}$ A. Inoue, Bulk Amorphous Alloys: Preparation and Fundamental Characteristics, Materials Science Foundations Vol. 4 (Trans Tech, Zurich, Switzerland, 1998).

${ }^{10}$ A. Inoue, Bulk Amorphous Alloys: Practical Characteristics and Applications, Materials Science Foundations Vol. 6 (Trans Tech Publications, Zurich, Switzerland, 1999).

${ }^{11}$ J. Shen, Q. Chen, J. Sun, H. Fan, and G. Wang, Appl. Phys. Lett. 86, 151907 (2005)

${ }^{12}$ A. Inoue, N. Nishiyama, and H. Kimura, Mater. Trans., JIM 38, 179 (1997).

${ }^{13}$ Q. Li, Mater. Sci. Eng., A 471, 75 (2007).

${ }^{14}$ C. Suryanarayana, Prog. Mater. Sci. 46, 1 (2001).

${ }^{15}$ C. Suryanarayana, Mechanical Alloying and Milling (Marcel Dekker, New York, 2004).

${ }^{16}$ S. Sharma, R. Vaidyanathan, and C. Suryanarayana, Appl. Phys. Lett. 90, 111915 (2007).

${ }^{17}$ W. H. Wang, Q. Wei, and H. Y. Bai, Appl. Phys. Lett. 71, 58 (1997).

${ }^{18}$ W. H. Wang and H. Y. Bai, J. Appl. Phys. 84, 5961 (1998).

${ }^{19}$ J. H. Kim, J. S. Park, H. T. Jeong, W. T. Kim, and D. H. Kim, Mater. Sci. Eng., A 386, 186 (2004).

${ }^{20}$ A. Inoue, Y. Shinohara, and J. S. Gook, Mater. Trans., JIM 36, 1427 (1995).

${ }^{21}$ M. Sherif El-Eskandarany, K. Aoki, K. Sumiyama, and K. Suzuki, Scr. Mater. 36, 1001 (1997).

${ }^{22}$ M. Sherif El-Eskandarany, K. Aoki, K. Sumiyama, and K. Suzuki, Appl. Phys. Lett. 70, 1679 (1997).

${ }^{23}$ M. Sherif El-Eskandarany, K. Aoki, K. Sumiyama, and K. Suzuki, Acta Mater. 50, 1113 (2002).

${ }^{24}$ W. C. Johnson, J. K. Lee, and G. J. Shiflet, Acta Mater. 54, 5123 (2006).

${ }^{25}$ M. Sherif El-Eskandarany and A. Inoue, Phys. Rev. B 75, 224109 (2007).

${ }^{26}$ T. A. Weber and F. H. Stillinger, Phys. Rev. B 31, 1954 (1985).

${ }^{27}$ G. S. Cargill III, J. Appl. Phys. 41, 12 (1970).

${ }^{28} \mathrm{~J}$. Dixmier and A. Guinier, in Physics of Non-Crystalline Solids, edited by J. A. Prins (North-Holland, Amsterdam, 1965), p. 67.

${ }^{29}$ F. R. de Boer, R. Boom, W. C. M. Mattens, A. R. Miedema, and A. K. Niessen, Cohesion in Metals: Transition Metal Alloys (North Holland, Amsterdam, 1988).

${ }^{30}$ E. S. Park and D. H. Kim, Acta Mater. 54, 2597 (2006).

${ }^{31}$ E. S. Park, D. H. Kim, T. Ohkubo, and K. Hono, J. Non-Cryst. Solids 351, 1232 (2005).

${ }^{32}$ A. Inoue, Y. Shinohara, and J. S. Gook, Mater. Trans., JIM 36, 1427 (1995).

${ }^{33}$ R. Sinclair, T. Itoh, and R. Chin, Microsc. Microanal. 8, 288 (2002).

${ }^{34}$ R. Sinclair and T. J. Konno, Ultramicroscopy 56, 225 (1994).

${ }^{35}$ Binary Alloy Phase Diagrams, edited by T. B. Massalski (ASM International, Materials Park, OH, 1986). 